suggest the question whether they are en irreconcilable either in method or in resulte as is commonly supposed; and whether the stigma so often affixed to all branches of the science of mind on account of the supposed conflict among its expounders is not greatly exaggerated Perfect agreement of course is not to be anticipated until the science has made much further progress, but there seems to me to be at present a much larger amount of it than the contending partie are perhape themselves aware of.

W. H. 8. Mosor.

\title{
ON THE FUNDAXENTAL DOOTRRTES OF DEBOARTES.
}

In Mr. Wallace's recently published book on Kant-which, on the whole, appears to me well and carefully written-I find the following summary (pp. 140-1) of the aims and drift of Cartesianism :

"Descartes like Bacon, made a protest against scholasticism. But whereas Bacon set on foot a movement outside the boundaries of the school, which grew and increased independently till it came back strong enough to reconstitute philosophy, Descartes was rather an internal reformer who sought to reconstruct the irregular edifice of medievalism on a new principle. That principle was the centrality and priority of thought. A clear and distinct conception was nade the certain evidence of reality and trath: cogito, ergo rum. Thus the negative criterion, that confusion and indistinctness indicate some error in our ideas, was at one tarn translated into the positive canon that whatever we clearly and distinctly think is true. What Descartes no doubt sought was to get rid of the eternal mentation, and to found the ultimate objects of belief on immediate or intuitive perception. We have, he says, certain ideas-notably the idea of God-which are unmistakable, and force themselves upon our thoughts whether we will or not: ideas which we do not voluntarily make, and which are the inevitable issue of our mental constitution; hence, argues Descartes, the objects of these idens exist independently of our thoughts, of which they 80 obviously are the masters It frould not be easy to determine how far these metaphysical presumptions are essential to Descartes : they certainly came to be the very essence of Cartesianism. Innate ideas thoughts which, just because they were universally or generically thought, were treated as evidence of a reality beyond the mind-came to be the recognised creed of the Cartesian school."

This passage is, I think, likely to give the general English reader a seriously inaccurate view of the fundamental doctrines of Descartes; and as the errors and confusions which it tends to suggest or confirm seem to be rather widely current, I should like to take this opportunity of pointing them out. The misapprehensions in question relate to two points in the Cartesian system, which it will be convenient to discuss separately, 80 far as possible: (1) the importance in the system of Descartes' doctrine as to the origin of ideas, and (2) the nature and extent of the inference drawn by Descartes from the existence of clear and distinct ideas in the mind to the existence of corresponding objects independently of the mind. I will begin with the second point as being both the more important and the more difficult. 
Mr. Wallace says that Descartes made a "clear and distinct conception" the "certain evidence of reality and truth"; and that be "songht to found the ultimate objects of belief on immediate and intuitive perception". Interpreting this last sentence by what follows the reader will naturally understand, as the cardinal doctrine of Descartes, that whenever we have clear and distinct conceptions or perceptions we may legitimately infer that corresponding objects exist independently of our thoughto-at any rate if the ideas of sach objects "force themselves on our thoughts whether we will or not". And he would certainly find this interpretation of the Cartesian doctrine more or less confirmed by the statements of several other writers. It is not difficult to show that it is an erroneous interpretation: at the same time I must admit that the responsibility for it rests primarily on Descartes himself, who formulated his criterion of truth in the careless phrase "les chases que nous concevons fort clairement et fort distinctement sont toutes vraies". Descartes knew as well as any one that truth is an attribute not of "things," strictly speaking, but of judgments or propositions; and if he had only stated explicitly what kinds of propositions "concerning real existence" - to use Locke's phrase-he regarded as guaranteed by his criterion, much confuaion might have been prevented. $A s$ it is, we have to gather his doctrine on this point from a comparison of various passages of his writings which it is not easy to make altogether consistent. Distinguishing conception and perception, we have to discover (1) whether Descartes meant that whenevier I form a very clear and distinct general conception, I know or may know that a class of objecte actually exist as so conceived, independently of my conception; and (2) whether he meant that from a clear and distinct perception I may eimilarly infer the existence beyond the mind of a particular object. The second of these propositions is substantially the doctrine of Common Sense (psychological subtleties apart): but the first appears 80 wild and 80 gratuitous a pararlox that I should hardly have thought of proving that Descartes did not hold it, if something very like it bad not been expressly attributed to him by writers of repute. For instance J. S. Mill, giving as a paraphrase of Descartes' "celebrated maxim" (Logic, B. V. c. iii. § 3) the proposition "whatever can be very clearly conceived must actually exist-that is if the idea includes existence,"-adds that Descartes " on this ground infers that geometrical figures really exist, because they can be distinctly conceived". In fact, however, Descartes selects this very instance in order to assure his readers that he infers nothing of the kind. " Having observed," he says, "that this great certitude which every one attributes to geometrical demonstrations is founded solely on their being clearly conceived, according to the rule already stated, I observed also that there was nothing at all in them which essured me of the existence of their object; for example, I clearly saw that, supposing a triangle to be given, its three angles must be equal to two right angles, but I did not therefore see anything which could assure me that any triangle actually existed " (De li Methode, iv.). Indeed the whole point of the 
ontological argument, in which the existence of God is inferred from the conception, is lost if we vaguely think with Mill that Descartes is prepared to draw a similar inference in the case of finite objects like triangles.

At the same time the statement of Mill above quoted must not be regarded as a quite inexplicable blunder. Its explanation is to be found in a passage in the Fifth Meditation, in which Descartes certainly gives goometrical figures as examples of a clase of "things which cannot be esteemed pure nonenties, and which are not feigned by me - . . but have true and immutable natures of their own ". Thus when I have imagined a triangle, I can demonstrate diverse properties of it, which "whether I will or not, I now clearly discern to belong to it, although I did not think of them when I imagined a triangle, and therefore they cannot be said to have been feigned or invented by me." And not merely of a triangle but of innumerable figures of which I cannot possibly have had scientific experience I can similarly demonstrate diverse properties, "which must certainly be all true since I clearly conceive them; and therefore they are something and not pure nothing: car il est tres-evident que tout 'ce qui est vrai est quelque chase, la verité etant uno mêmo chase que lêtre". It is this last sentence which bas misled Mill, who seems to have failed to catch Descartes" distinction between the "being" thus identified with the trath of geometrical propositions, and the "existence" independent of thought which Descartes expresaly abstaing from attributing to the geometrical figuree. And I am afraid that the distinction has also escaped the attention of Prof. Veitch, in whose excellent translation of the Moditations I find "être" in this passage rendered "existence". Indeed the sentence quoted mast be admitted to be mysterious and obscure to a plain reader; and probably Descartes felt this, as we find that in the quasi-geometrical demonstration of his main doctrines which forms the termination of his reply to the Second Objections to his Meditations, he makes the real meaning of the above sentence more plain in the form of the following axiom :

"Dans l'idée ou le concept de chaque chose, l'existence y est contenue, parceque nons ne pouvons rien concevoir que sous la forme d'une chose qui existe ; mais avec cette difference, que dans le concept d'une chose limitée, l'eristence possible et contingente est seulement contenue, et dans le concept d'un être souverainement parfait, la parfaite et necessaire y est comprise.

That is, the criterion of "clear and distinct" conception guarantees the passithe existence of the object conceived, in the case of finite objects; it guarantes necessary existence, in the single case of the Infinite and Perfect Being; but it can never warrant us in concluding that any finite object actually existe independently of the mind.

It remains to ask whether, in Descartes' view, this latter conclusion is immediately warranted by clear and distinct perception of a particular object-whether I bave the ame kind and degree of cartitade that this paper on which I write actually exists beyond noy mind, as I have that matter generally with spatial attributes may exist indepen- 
dently of mind. Had Descartes answered this question in the affirmative, his doctrine (as I have said) would be only distinguished by a fine shade from Nataral Dualism. But the language of the Third Meditation is quite irreconcilable with this interpretation of his view. He there draws a sharp distinction between a natural inclination to a certain belief and the natural light which makes me know it to be true. I cannot, he says, doubt what the natural light makes me to be true (as e.g., my own existence or geometrical axioms) : but as for mere natural inclinations, - they frequently lead me wrong in action, and I must therefore regard them as untrustworthy guides to belief. And when I say that I am " taught by nature" to refer my ideas of material thing to similar objects actually existing without my mind, I meraly mean that I have an inclination to believe in the actual existence of such objecte, not that their existence is shown to me by the natural light. Hence the actual existence of the individual things that I seem to perceive must be regarded as prima facic dnbitable; and only capable of being established indirectly by proving the existence of God and relying on the Divine reracity.

The passage just referred to is so clear, and so entirely in harmony with the whole of Descartes' teaching, that I should have not thought it needful to Iabour this point, had it not been for a passage in his Principles which at first sight appears to enggest a different view. He there says (Princ. Pt. II \&1) that our senses "often stimulate us to perceive clearly and distinctly a matter extended in length, breadth, and thickness "\&c. If this passage stood alone, I should certainly have understood it to imply that the actual existence without the mind of the particular matter percoived was guaranteed by Descartes' fundemental criterion. But, as it is, the passage has to be interpreted in the light of the more fall and explicit statement in the Third Meditation: and when we look closely at it in this light it will, I think, become plain that what Descartes regards as clearly and diatinctly apprehended is merely the particular extension of the matter perceived and not its actual existence without the mind. In short, in the Principles no less than in the Meditations Descartes admits what Kant calls a "problematical Idealism"; only in the later treatise the problem is more swiftly and sammarily brought to its realistic solution.

Let us now turn to the question of origin According to Mr. Wallace's statement, the inference which he describes Descartes as making from the existence of ideas in the mind to the existence of corresponding objects beyond the mind does not appear to be legitimated simply by the criterion of clear and distinct thought; it is dependent on the condition that the ideas in question are " not voluntarily made," but are "the inevitable issue of our mental constitation". Now it is true, as we have seen, that the validity of axioms or theorems relating to geometrical figures-as representative of the "true and immutable natures" of such figures-is inferred by Descartes from the fact that the mind finds itself in a manner constrained to conjoin the predicates of such propositions with their subjects; thus it is open to me to abstain from conceiving a triangle, but if $I$ conceive it, I cannot now avoid 
seaing, whether I will or no, that its three angles are equal to two right angles But as I have said, in knowing what is affirmed in such propositions, I know nothing about actual existence beyond the mind, I merely know certein universal conditions or laws of passible existence. And I do not think that Descartes ever infers either (1) from the innateness or (2) from the involuntariness of any ideas the actual existence of their objects without the mind.

In discuseing this it will be convenient to consider each of these two characteristics separately, since, though Mr. Wallace's statement mixes them up in a curious way, they are never so connected by Descartes. In the pesage of the Third Meditation to which I have already referred he makes a threefold division of ideas in. respect of their apparent origin, distingaishing (1) the apparently innate, (2) the apparently adventitious, and (3) those voluntarily invented by myself. The second class, which "seem to come from certsin objects without $m e$," are-no less than the innate-independent of my will; and this is undoubtedly a reason which leads me to think that they really do come from external objects like them. But, in Descartes' judgment, it is not an adequate ground for this conclusion: for, as he says, " peut-stre qu'il y a en moi quelque faculté ou puissance propre a prodaire ces idées sans l'aide d'aucunes choses extérieures, bien qu'elle ne me soit pes encore connue; comme en effet il m'a toujours samblé jusques ici que lorsque je durs elles se forment ainsi en moi sans l'aide des objets qu'elles representent". I cannot therefore regard the involuntariness of any of $\mathrm{my}$ ideas as proving the existence beyond my mind of objects like them, or even the existence of things different from myself at all.

Does, then, "innateness" furnish such a proof i I cannot 800 that Descartes anywhere affirms or even implies this. The only idea $\rightarrow$ as distinct from axiom or principle-that he expressly affirms to be innate is the idea of an Infinite and Perfect Being. But though, in this one case, he certainly believes the actual independent existence of such a being to be demonstrable from -what may be known of the origin of the idee, his argument does not rely upon the innateness of this ides, but upon the peculiar impossibility of its being originated by a finite mind (or anything else finite). All ideas that represent modes of finite substances might be involuntarily and unconsciously produced by himself : but the idea of an infinite substance cannot, he thinks, be so produced; nothing can be adequate to produce it except the infinite substance that it represente. Hence in this one case we may argue from the existence of the idea in the mind to the independent existence of its object, as being its only possible cause. He certainly holds the idea to have been implanted by God in creating the mind, since there is no point in the mind's experience at which the idea is suddenly presented from without; but (I repest) his inference from the ides to the independent reality in no way depends upon the innateness of the former.

Similarly, while holding that various "etermal trutbs" have their " seat in our thought," and are thus in some sense innste, he nowhere 
rests his certitude so to their truth on their innateness. So far from regarding the dectrine of innate ideas or principles as a fundamental part of the Cartesian system, I should be inclined to say, on the contrary, that Descartes' new criterion of certitude has the effect of rendering the question of innateness philosophically unimportant: if the truth of an axiom is adequately guaranteed by the clearness and distinctness with which it is intuitively apprehended, our belief in it needs no further philosophical basis or warrant ; it is therefore superfluous to inquire into its innateness. In fact I should say that when Locke declares that "self-evidence does not depend upon innate impressions" but on the perception of the agreement or disagreement of "clear and distinct ideas," he is really availing himself of a position essentially Cartesian to attack a doctrine which Descartes' system certainly retained, but which it could have spared without any sensible lose.

H. Smowiok.

THE MNHMONIO LINES OP THE BYLLOAI8Y.

Well it might be if it were now too late in the career of civilisation to write notes on the above subject. But it would be a mark of the sanguine temperament to think so. Too probably the Mnemonic Lines of the Syllogism will long continue to exemplify the union of vanity with vexation of spirit, and if so, the teacher of Logic -will often have occasion to reflect that with all their excellence they are not impeccable. These rerses, which embody the names of the legitimate Moods, and signify the processes by which Moods of the 2nd, 3rd, and 4th Figures may be reduced to their equivalents in the lst Fig., have in fact three conspicuous faults: (1) they provide no means of reminding us, without reciting the whole, to which Figure any Mood belongs; (2) some letters occurring in the names, viz, $l, n, r, t$, have no significance; and (3) there are no names to indicate the direct reduction of Baroco and Bocardo by means of obversion and contraposition. But happily a fow slight alterations will remedy all these shortcomings.

To what Figure any Mood belongs may be shown by inserting in all names of Moods of each Figure an appropriate letter; and neatness would be gained by using for this parpose the four liquids in the order they have in the alphabet; but as $m$ already stands for mutation of premisses, this is undesirable. The next suggestion is to utilise the letters $l, n, r, t$, at present occurring in the rerses without import; and of course to take them in alphabetical order. Let $l$, then, be the sign of the 1st Fig., $n$ of the 2nd, $r$ of the 3rd, and $t$ of the 4 th. Thus the first two imperfections will be rectified at once.

For attempting to form new names instead of Baroco and Bocardo, such as may indicate their direct reduction by means of obversion and contraposition, there is the anthority of Archbishop Whately, who proposed to call them respectively Fakoro and Dokamo: $F$ and $D$ 